\title{
Cova da Moura: identidad caboverdiana y conflicto urbano en la periferia de Lisboa
}

Francisco Cuberos-Gallardo. Instituto Universitário de Lisboa (CIES-IUL), Lisboa, Portugal.

RESUmen | El barrio de Cova da Moura se ubica en la periferia de Lisboa, y ha estado desde sus inicios fuertemente vinculado al origen inmigrante de sus siete mil vecinos. A lo largo de cuarenta años, estos han impreso a los espacios del barrio usos, formas y significados que reivindican expresamente la identidad caboverdiana. El objetivo de este trabajo es reflexionar sobre este singular proceso de territorialización y enmarcarlo en el contexto de conflictividad urbana que lo dota de sentido. Para ello se realiza una descripción etnográfica de la evolución de este barrio, atendiendo tanto al papel desarrollado por actores externos -administración pública y empresas- como a las estrategias de autoorganización articuladas por los vecinos.

PALABRAS ClAVE | conflicto social, migración, urbanismo.

ABSTRACT | The neighbourhood of Cova da Moura is located on the outskirts of Lisbon and since its foundation it has been strongly linked to the immigrant origin of its seven thousand inhabitants. For forty years they have given uses, forms and meanings to the neighbourhood space, which expressly claimed the Cape Verdean identity. The aim of this paper is to reflect on the process of territorialisation and frame it in the context of urban conflict, which contributes to its underlying meaning. We present an ethnographic description of the evolution of this neighbourhood, attending to both the role played by external actors-public administration and companies-and the self-organizing initiatives articulated by neighbours.

KEYWORDs | social conflict, migration, urbanism. 


\section{Introducción}

El barrio de Cova da Moura se ubica dentro del concelho (distrito municipal) de Amadora, en la periferia de Lisboa, y ha estado desde sus inicios fuertemente vinculado al origen inmigrante de sus siete mil vecinos. Estos llegaron a la zona a comienzos de los ańos setenta para trabajar en una industria incipiente que precisaba de mano de obra barata y poco cualificada. Entre ellos hay portugueses originarios del medio rural, especialmente del Alentejo, así como africanos procedentes de las antiguas colonias portuguesas: guineanos, angoleños, mozambiqueños y caboverdianos. Estos últimos, que destacan en número y aglutinan aproximadamente al $60 \%$ de la población de Cova da Moura, han logrado desarrollar un fuerte proceso de territorialización, imprimiendo a sus espacios de residencia ciertos usos y formas que reivindican expresamente la identidad caboverdiana. Estos se condensan en la palabra isla, que utilizan para referirse al barrio, subrayando tanto su diferencia respecto al entorno lisboeta, como su integración simbólica en el archipiélago caboverdiano. La Cova da Moura ha sido así configurada como un enclave caboverdiano en Lisboa. El objetivo de este texto es reflexionar sobre este singular proceso de territorialización y enmarcarlo en el contexto de conflictividad urbana que lo dota de sentido.

El objeto de nuestro trabajo nos remite de lleno a una problemática de larga tradición en los estudios sobre la ciudad, como es la incorporación de las minorías inmigrantes y de sus culturas al espacio urbano. Los sociólogos de la Escuela de Chicago, pioneros en el abordaje del problema, plantean un enfoque que observamos sintetizado en la famosa obra El campesino polaco (2004), de Thomas y Znaniecki. Dicho enfoque utiliza la noción de "ecología humana" para establecer una correlación entre estructura espacial y estructura social, entendiendo el comportamiento de los grupos humanos como respuestas adaptativas a su espacio y a su cultura. En el Chicago de las décadas de 1920 y 1930, afectado por problemas de crecimiento urbano acelerado, marginación y delincuencia, las culturas de los inmigrantes que llegaban a la ciudad fueron interpretadas como desestructuradas y disfuncionales en el proceso de adaptación. Sin embargo, trabajos posteriores han argumentado, especialmente a lo largo de los últimos cincuenta años, que en determinados contextos la resistencia a la asimilación cultural puede ser para las minorías una estrategia coherente de inserción urbana. Así lo argumentaron Glazer y Moyniham (1979) al cuestionar abiertamente la idea del melting pot y demostrar que en Nueva York los grupos étnicos minoritarios planteaban formas coherentes de resistencia cultural a la presión asimilacionsita de los WASP (Hutchinson \& Smith, 1996, p. 133). En nuestro trabajo se reivindica esta concepción alternativa del papel de la cultura de origen y la identidad de los inmigrantes en el proceso de integración a la ciudad. Se parte de que dichas estrategias no tienen por qué resultar un hándicap, pudiendo operar, por el contrario, como un recurso que permite a los inmigrantes articular respuestas eficientes a sus nuevos problemas (Martín, 1990; Martín \& Pujadas, 1999).

La Cova da Moura ofrece un escenario privilegiado para el análisis de procesos de inserción urbana entre poblaciones inmigrantes. Este barrio se sitúa dentro de la ciudad de Amadora, una municipalidad perteneciente al área metropolitana de Lisboa e inscrita de facto en el trazado urbano de la capital portuguesa. Amadora 
cuenta en la actualidad con 175.136 habitantes distribuidos dentro de uno de los términos municipales más pequeños de Portugal, convirtiéndose así en la ciudad con mayor densidad de población de todo el país. Habiendo pertenecido durante varias décadas a la municipalidad de Oeiras, en 1979 se independizó de esta y quedó constituida como cámara municipal, ${ }^{1}$ en respuesta a un crecimiento poblacional acelerado que es indisociable de la instalación en la zona de miles de inmigrantes procedentes de las antiguas colonias portuguesas. Desde entonces han sido muchos los barrios de esta ciudad atravesados por fuertes conflictos urbanos en los que el problema de la propiedad de los terrenos se articula con otros derivados de la falta de infraestructuras, la pobreza, la marginalidad y la precariedad jurídica de los inmigrantes. Será en este contexto de alta conflictividad que la Cova da Moura albergará un proceso de territorialización específico y crecientemente orientado a la visibilización y a la reivindicación orgullosa de la identidad caboverdiana.

El caso de estudio que se presenta posee características singulares que le confieren un especial interés. Por una parte, nos encontramos con un vínculo peculiar entre este barrio y sus habitantes pues siendo estos inmigrantes, fueron también quienes levantaron físicamente las casas y calles de este vecindario portugués y quienes se consideran, por tanto, los habitantes originarios de este territorio y sus ocupantes legítimos. Esta situación tendrá -como veremos- consecuencias importantes en los conflictos que se han ido desarrollando durante los últimos años con las autoridades municipales, que ponen en tensión el debate sobre la pertenencia al territorio y su legitimidad. Por otro lado, se observa que el paso del tiempo no ha contribuido a debilitar la identidad cultural de los vecinos caboverdianos, la cual, por el contrario, se ha visto crecientemente reafirmada a lo largo de cuatro décadas. Este dato nos impide explicar el apego a la cultura propia en términos de mera continuidad con la experiencia en el país de origen, y nos obliga a buscar su explicación dentro del espacio-tiempo que habitan en el presente. Finalmente, el caso estudiado ofrece una posibilidad interesante para incorporar al análisis de la construcción de la identidad del barrio el papel desempeñado por actores externos, como empresas privadas y autoridades públicas. Tal y como detallaremos en la etnografía, el papel protagonista de la identidad caboverdiana en el barrio debe ser enmarcado en el régimen de relaciones que los vecinos de este territorio en particular han ido estableciendo con el exterior; unas relaciones que se han desarrollado en la forma de un conflicto permanente pero de características variables, y que ha evolucionado desde el abandono del barrio hasta su acoso por intereses especulativos.

El texto que se presenta está basado en un trabajo de campo de un año de duración, que se enmarca dentro del proyecto "The role of immigrant associations in the integration process. Comparing pos and political cultures in the cities of Seville and Lisbon", 2 y que fue desarrollado durante la segunda mitad de 2013 y la primera

1 Las cámaras municipales asumen el grueso de las competencias políticas en el plano local, y equivalen aproximadamente a los ayuntamientos españoles y las municipalidades de numerosos países latinoamericanos.

2 Proyecto financiado como beca posdoctoral por la Fundação para a Ciência e a Tecnologia (FCT, Ministério da Ciência, Tecnologia e Ensino Superior de Portugal). Referencia: SfrH/ $\mathrm{BPD} / 85438 / 2012$ 
de 2014. Para el abordaje de los datos primarios se optó por una metodología de base cualitativa, sustentada en la observación participante y en la realización de entrevistas en profundidad a los vecinos de la zona. Los ejercicios de observación atendieron a los modos de sociabilidad entre los vecinos, y en ellos se prestó especial atención a las redes de relaciones que los unen, al uso de los espacios y a la construcción discursiva de fronteras dentro y fuera del barrio. Las entrevistas tuvieron como objetivo la captación de la experiencia de los vecinos a través de sus propios discursos. Fueron aplicados dos guiones de entrevista diferentes: uno más corto, usado para registrar la experiencia y las opiniones de una veintena de vecinos, incluyendo a hombres y mujeres de diversas nacionalidades -caboverdianos, portugueses, angoleńos y guineanos-, y con diferentes niveles de antigüedad en el barrio; y uno segundo más extenso, que fue reservado a un número pequeño de informantes clave que han tenido un papel especialmente destacado en la gestión de los conflictos barriales y en las estrategias de autoorganización de los vecinos. Este segundo guion se orientó a reconstruir en detalle la trayectoria de las personas entrevistadas y a profundizar, a través de sus palabras, en la descripción de la historia del barrio. Adicionalmente, la información recogida sobre el terreno fue complementada con la consulta sistemática de documentación bibliográfica y material audiovisual sobre inmigración caboverdiana en Portugal, y especialmente de los trabajos ya realizados en este barrio y su entorno. Paralelamente, nos hemos apoyado en la consulta de fotografías producidas por los propios vecinos y asociaciones del barrio, así como de numerosas noticias aparecidas en medios de comunicación - prensa y televisión- y algunos vídeos y documentales de especial interés. ${ }^{3}$

A continuación dedicamos un apartado a perfilar los conceptos teóricos que sustentan este trabajo. Posteriormente exponemos los datos recabados en esta investigación, agrupándolos en tres epígrafes. En el primero se describe los orígenes del barrio y su conexión con la migración caboverdiana en el contexto de descolonización portuguesa. El segundo y el tercer apartado de la etnografía son dedicados a analizar los conflictos que han afectado a este barrio y las respuestas organizadas de la población caboverdiana, a partir de la delimitación de dos etapas claramente diferenciadas que se corresponden con cada uno de estos dos apartados. Finalmente se incluye un breve apartado de conclusiones, con el objetivo de recapitular las ideas fundamentales del texto y proponer otras para la reflexión teórica.

\section{Inmigración, identidad y conflicto en el medio urbano}

Si la identidad caboverdiana desempeña hoy un papel central en la vida social de la Cova da Moura es por su papel vertebrador de la resistencia vecinal en un contexto marcado por fuertes conflictos dentro y fuera del barrio. Esta propuesta interpretativa nos obliga a reflexionar de antemano sobre el papel determinante del conflicto como lógica estructural en los modos de apropiación del espacio urbano, y sobre la función central que las identidades étnicas han ido asumiendo en la vertebración de 
estos conflictos. En efecto, la teoría de la producción social del espacio ha demostrado en diferentes momentos y contextos cómo, en el marco del modelo de producción capitalista, el espacio pasa a ser un recurso más en la lucha que grupos desiguales libran entre sí. Así lo observa Lefebvre en The Production of Space (1991), Castells en The Urban Question (1977), Harvey en Social Justice and the City (1973) y Lojkine en Marxism, the State and the Urban Question (1981). Todos estos autores, sin embargo, trabajaron en un contexto de capitalismo fordista marcado por la predominancia de la producción en los modos de acumulación, lo cual determinaba una necesidad estructural de mano de obra, que a su vez establecía la centralidad de la clase trabajadora como elemento de identificación para la mayoría social, y de la clase social como criterio organizador del conflicto en el medio urbano.

En la medida en que el fordismo va siendo sustituido por el actual modelo de globalización, la producción pierde relevancia frente a la economía financiera de base especulativa, y ello se traduce en una reorganización de las relaciones entre capital y trabajo. La creciente movilidad del capital y menor dependencia del factor trabajo se plasma en mercados de trabajo transnacionales y fuertemente precarizados. En este contexto, autores como Sassen (2003, p. 109) y Castles (1998, p. 7) llaman la atención sobre la nueva centralidad del medio urbano como escenario de conflictos en que también las poblaciones migrantes son protagonistas. La ciudad se torna un espacio político más concreto que la nación (Isin, 2000; Sassen, 2000), y es en este nivel geográfico donde los inmigrantes desarrollan sus estrategias de resistencia (Castells, 1997, pp. 366-367; Sassen, 2003, p. 113). Dentro de estas nuevas dinámicas de conflicto, la etnicidad tendrá un rol central.

La identidad étnica va a ser el elemento aglutinante de amplias capas de población inmigrante que, en el marco de precariedad jurídica, laboral y residencial en que viven, precisan dotarse de redes que, a través del apoyo mutuo, estructuran el acceso a importantes recursos materiales y simbólicos (Cuberos-Gallardo, 2014). Para estos nuevos vecinos, la sociabilidad en los barrios de inserción se orienta en gran medida al refuerzo de redes intraétnicas que, además de reportarles apoyo psicológico y emocional, permiten la vertebración de cauces de información, recursos y formas específicas de ayuda (Gurak \& Caces, 1998). Consecuentemente, se dan en estas poblaciones de inmigrantes formas específicas de territorialización, entendiendo esta como el proceso de apropiación, delimitación y definición funcional del espacio que cada grupo lleva a cabo de manera coherente con su identidad (Garcés, 2006, p. 6). Así, y cuando esta población se encuentra dispersa e invisibilizada, como en el caso paradigmático de las mujeres migrantes que trabajan como internas en el servicio doméstico, se constata una tendencia a la apropiación intensiva de espacios públicos específicos durante las horas de tiempo libre -generalmente durante el fin de semana-, tal y como fue constatado por Law (2002) entre las filipinas residentes en Hong Kong y por Cuberos-Gallardo (2009) entre las ecuatorianas residentes en Sevilla. En estos casos, y debido al escaso margen de autonomía de estas poblaciones, sus modos de territorialización son precarios y discontinuos. En la Cova da Moura la presencia de los inmigrantes, concentrada en el espacio y consolidada a lo largo del tiempo, permite el trazado de estrategias de territorialización caracterizadas por un alto grado de conciencia, constancia y eficacia. La forma en que la población caboverdiana de la 
Cova da Moura se ha apropiado de los espacios del barrio, y el modo en que los carga de significado, refleja ya un análisis propio de la situación que obedece a criterios estables y objetivos bien definidos. La territorialización de la Cova da Moura como un enclave étnico caboverdiano debe ser interpretada como una estrategia de resistencia organizada frente a las imposiciones de actores más poderosos, que pugnan por dotar de otros usos, funciones y significados a ese mismo espacio.

La tendencia a apropiarse de espacios urbanos en tanto estrategia de resistencia de grupos subalternos constituye una constante en las sociedades contemporáneas. Winchester, Kong y Dunn (2003) han recapitulado en sus trabajos ejemplos diversos, incluyendo la oposición organizada de la comunidad sikh a realojar sus templos en Singapur; la resistencia de los vecinos de Dayton (Texas, EE.uU.) a la instalación de una empresa de eliminación de residuos; o la conformación de barrios gay en diversas grandes ciudades del orbe. En todos estos casos, la reivindicación del territorio y su resignificación permiten la canalización de formas de resistencia al estigma y a la exclusión.

También en este trabajo nos acercamos al espacio urbano en tanto expresión de relaciones de dominación y de resistencia. Partimos de que al dar al espacio nuevos usos y significados, los inmigrantes subvierten y/o niegan política y simbólicamente su propia exclusión. El espacio del barrio pasa a ser más que un mero escenario del conflicto social, para convertirse en un recurso estratégico que es al mismo tiempo condicionante y resultado del conflicto. Para entender esta relación dinámica y dialógica entre conflicto, identidad y territorio se hace necesario reconstruir de manera diacrónica la acción de los sujetos implicados en nuestro caso de estudio, comenzando por enmarcar el origen del barrio en su contexto histórico.

\section{Contextualización: inmigración caboverdiana en la periferia de Lisboa}

La periferia de la ciudad de Lisboa acoge, en concelhos como Loures, Odivelas o Amadora, a la mayor parte de los 42.857 caboverdianos que actualmente residen en Portugal, según el Servicio de Extranjeros y Fronteras (2013). A esta cifra, que convierte a los nacionales de Cabo Verde en tercera minoría inmigrante del país -tras brasileños y ucranianos-, debemos ańadir la importante presencia de descendientes de caboverdianos, cuya suma arroja un cómputo global que estima la población de origen caboverdiano en torno a las 80.000 personas, incluyendo a los indocumentados y a los ya nacionalizados (Batalha, 2008). ${ }^{4}$

Esta presencia caboverdiana en Lisboa conecta con la fuerte tradición migratoria de la excolonia portuguesa, que ya en los siglos XVII y XviII comenzaba a expulsar grandes contingentes de población a raíz de la desertización provocada por la incorporación de un inadecuado modelo agrícola por parte de agricultores procedentes del Alentejo. En esta primera etapa, la migración se concentró en Guinea-Bissau, y en menor medida en Angola, Mozambique, Senegal y Brasil, estimulada por las

$4 \overline{\text { A partir de la reforma de la Ley de Nacionalidad en 1981, el criterio jurídico de reconocimiento de }}$ la nacionalidad portuguesa es el ius sanguinis. Desde entonces, el nacido de padres caboverdianos es caboverdiano, pese a haber nacido en Portugal. 
desigualdades inherentes al sistema colonial portugués y por la escasa pluviosidad en las islas y la pobreza de sus suelos (Carita \& Rosendo, 1993, p. 141). A comienzos del siglo $\mathrm{xx}$, los flujos migratorios se reorientaron hacia Estados Unidos, y más tarde a Brasil y Argentina. Y fue en la segunda mitad de este siglo cuando los caboverdianos empezaron a migrar a Europa, primero a Escandinavia y Europa central -Francia, Luxemburgo-, y más tarde a Italia y Portugal. Desde fines de los ańos sesenta, la migración caboverdiana se concentró casi exclusivamente en Portugal, y muy especialmente en Lisboa y su área metropolitana.

Si bien en una primera fase esta migración se encuadró en un único espacio lusófono sometido al control del imperio portugués con sede en Lisboa, la independencia de Cabo Verde en 1975 no detuvo este flujo migratorio hacia la exmetrópoli, el cual siguió operando incluso con mayor intensidad que en los años precedentes (Carita \& Rosendo, 1993, p. 142). Ahora bien, si durante los últimos ańos del periodo colonial (1968-1974) esta corriente de caboverdianos se vio estimulada desde la metrópoli y estuvo compuesta mayoritariamente por estudiantes y cuadros formados en la administración colonial, tras la descolonización Portugal acogió -contra su voluntad, o al menos al margen de ella- a una población negra y mulata, de escasa cualificación, que alcanzó cifras especialmente destacadas en el periodo 1974-1981.

La inserción de este segundo contingente se desarrolló en condiciones de extrema precariedad laboral y residencial, y su integración en la sociedad portuguesa fue notablemente más dificultosa que la de aquellos caboverdianos llegados antes de la independencia (Batalha, 2008; Carita \& Rosendo, 1993; Sardinha, 2004). Fue esta población la que se asentó de manera concentrada en la periferia del Área Metropolitana de Lisboa, en una tendencia que respondía a la confluencia simultánea de varios factores. En primer lugar, coincide en estas fechas el despegue de una incipiente industria en la zona, que demandará una alta cantidad de mano de obra. Esta demanda, que en una primera etapa se había nutrido de portugueses procedentes del medio rural, encontrará ahora en los caboverdianos una fuerza de trabajo numerosa y más barata. En segundo lugar, la periferia ofrece un amplio espacio de terrenos vacíos, y en su mayor parte abandonados, que han permitido a los caboverdianos instalarse con una inversión mínima de capital.

Es así como miles de inmigrantes caboverdianos se han ido asentando en los municipios del extrarradio lisboeta, principalmente a lo largo de la antigua carretera militar que circunda la ciudad -la conocida Estrada Militar- y en torno a los principales nodos de transporte. La Cova da Moura ofrece un emplazamiento privilegiado, con un acceso directo a las líneas ferroviarias que conectan la ciudad de Sintra con la capital. Situados sobre una colina, estos terrenos se encuadran en su mayor parte dentro de una finca de titularidad privada, que a comienzos de los setenta se encontraba en estado de semiabandono y presentaba, por tanto, condiciones idóneas para la instalación de los nuevos vecinos. El vecindario de la Cova da Moura fue creciendo a partir de 1974 mediante la ocupación ilegal de terrenos, en un proceso que en sus primeros momentos contó con el beneplácito de las autoridades locales (Malherios \& Mendes, 2007), pero que pronto favorecería una asociación simbólica entre la población inmigrante y un medio físico y social degradado, lo cual ha marcado decisivamente la percepción social de este barrio. 


\section{FIGURA I Imagen panorámica del barrio Cova da Moura}

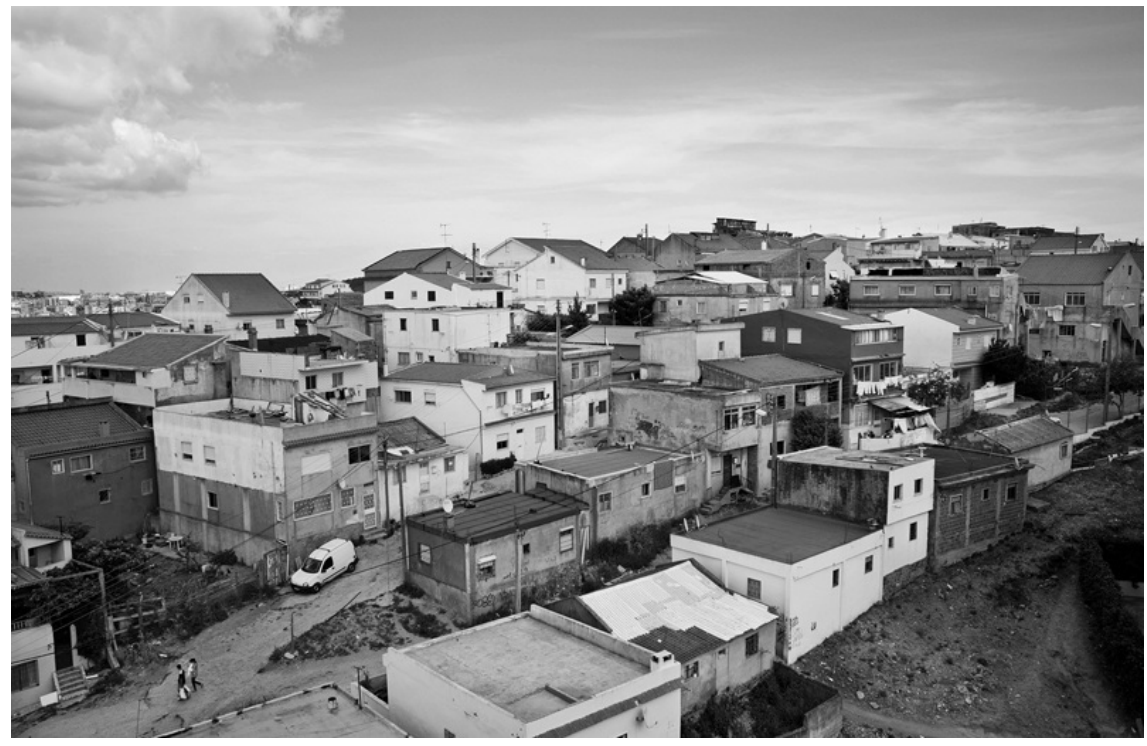

FUENTE JORGE HUMBERTO FERNANDES. HTTP://PPL.COM.PT/PT/PRJ/COVA-DA-MOURA

Desde esta primera fase, y durante veinte años, la población caboverdiana siguió creciendo en Amadora, y surtiendo de mano de obra tanto el programa de reestructuración económica del Distrito de Lisboa en los ochenta (Sardinha, 2009, pp. 107-108), como el fuerte crecimiento de la construcción civil en torno a la Expo'98 (Machado 1999, p. 58). A lo largo de este periodo, la Cova da Moura fue consolidando su condición de barrio africano y albergando en su seno elevados niveles de pobreza y marginación social, que a su vez motivaron el desarrollo de una problemática de creciente complejidad. Será precisamente la dureza de esta situación, y la escasez de recursos para hacerle frente, la que exigiría de los vecinos de este barrio la forja de densas redes de apoyo mutuo, basadas en fuertes lazos vecinales con un alto componente de solidaridad (Malheiros \& Mendes, 2007, p. 197).

Los orígenes de la Cova da Moura reflejan ya un proceso muy particular de configuración espacial, en el que un colectivo específico, el de los inmigrantes caboverdianos, desarrolla un peculiar ejercicio de territorialización. Al llegar a la zona, estos inmigrantes encontraron como primer problema la necesidad de dotarse de un refugio estable en terrenos vacíos y carentes de las más elementales infraestructuras urbanísticas. Así, en una primera fase el barrio fue habitado mediante la construcción de barracas, que solo con el transcurrir del tiempo se vieron sustituidas progresivamente por viviendas de mejor calidad. La construcción de la barraca era llevada a cabo durante la noche y en el escaso tiempo libre que dejaban las largas jornadas laborales. En esta tarea participaban todos los miembros de la familia, ejerciendo los adultos como peones de obra y los niños como asistentes en labores de carga y transporte de materiales. No obstante, las labores más pesadas de la construcción de la barraca, como la colocación del techo, exigían la prestación de ayuda voluntaria entre 
vecinos. Y paralelamente, la distribución espacial de las barracas y la delimitación del trazado urbano exigieron igualmente un alto grado de cooperación entre los vecinos del barrio, que en seguida cuajó en densas redes de sociabilidad intrabarrial.

Estas redes pronto fueron asumiendo nuevas funciones para afrontar los múltiples problemas derivados de la instalación en el barrio. La dureza del contexto de recepción llevó a que, para estos migrantes, organizarse y ser solidarios apareciera como requisito indispensable si querían seguir existiendo como comunidad (Pujadas, 1990, p. 315). La necesidad de limpiar los terrenos, construir las casas, ordenar las calles y obtener servicios básicos los empujó a entablar formas organizadas de solidaridad entre ellos. La carencia de abastecimiento básico de luz, agua y alcantarillado constituyó un factor determinante en la articulación de la lucha frente a la administración local, acción que se nutrirá de las redes solidarias existentes y que pronto se plasmará en la vertebración de un sólido tejido asociativo en el barrio. Vemos así cómo esta población va desarrollando, desde su llegada a Lisboa, un fuerte sentimiento de comunidad, que de un lado se apoya en un sustrato étnico compartido y de otro, en la necesidad de unir fuerzas para afrontar problemas comunes. La construcción física del barrio se verá trenzada desde su origen con la historia de estos inmigrantes, que dotarán a estas tierras abandonadas de un principio de sentido, habitando el espacio antes vacío y convirtiéndolo así en un lugar propio (Augé, 2002). Este proceso se irá configurando de manera discontinua, y al ritmo de un contexto afectado por fuertes conflictos urbanos.

\section{La construcción del barrio (1974-2000)}

La identidad caboverdiana ha operado como un importante recurso en la articulación de las estrategias de lucha de estos vecinos. La participación de esta identidad dotó a los residentes de la Cova da Moura de un criterio de cohesión y de límites grupales definidos, pero también de códigos propios y referentes compartidos. El proceso de autoorganización de estos inmigrantes se vio reforzado desde sus orígenes por el recurso sistemático a tradiciones y modos de sociabilidad directamente importados de las islas. Especialmente llamativo es el caso del djunta-mon, una práctica organizada de ayuda mutua ejecutada sistemáticamente por los vecinos del barrio para el abordaje de múltiples problemas.

Djunta-mon es una expresión que en criollo caboverdiano equivale a "juntar las manos" y que designa un sistema de prestación de ayuda voluntaria entre particulares que implica la obligación para quien recibe la ayuda de devolverla en condiciones equiparables. Con una lógica similar a sistemas como la minga andina o el ayni practicado por comunidades quechua y aymara, el djunta-mon debe su origen a la peculiar climatología del archipiélago caboverdiano, donde la concentración en el tiempo de las escasas lluvias provoca que el grueso de las tareas agrícolas deba realizarse en pocas semanas, lo que implica que durante ese tiempo deba movilizarse más fuerza de trabajo de la que cada propietario puede aportar por sí solo. El djuntamon permite recabar la ayuda de los vecinos a cambio de devolverla en formas y plazos más o menos acotados. Durante el tiempo en que la prestación de trabajo se materializa, el receptor de este trabajo compensa simbólicamente con la invitación 
a comida y bebida. Y este sistema, que ya había sido aplicado a muchas otras tareas en Cabo Verde -siendo documentado, por ejemplo, entre las mujeres de Praia para el cuidado de nińos-, pronto fue adoptado en el contexto migratorio. La primera aplicación observable se dio en la construcción de las barracas de los caboverdianos:

Cuando llegué al barrio aquí no había casas, no había nada: solo barracas de madera. Para hacer las casas, ayudaban los vecinos. Usted hablaba con los colegas para hacerla. (João Lucio, caboverdiano vecino del barrio)

FIGURA 2 | Un grafiti a la entrada del barrio homenajea a la institución del djunta-mon (o djunta-mo) y a la fiesta de Kola San Jon

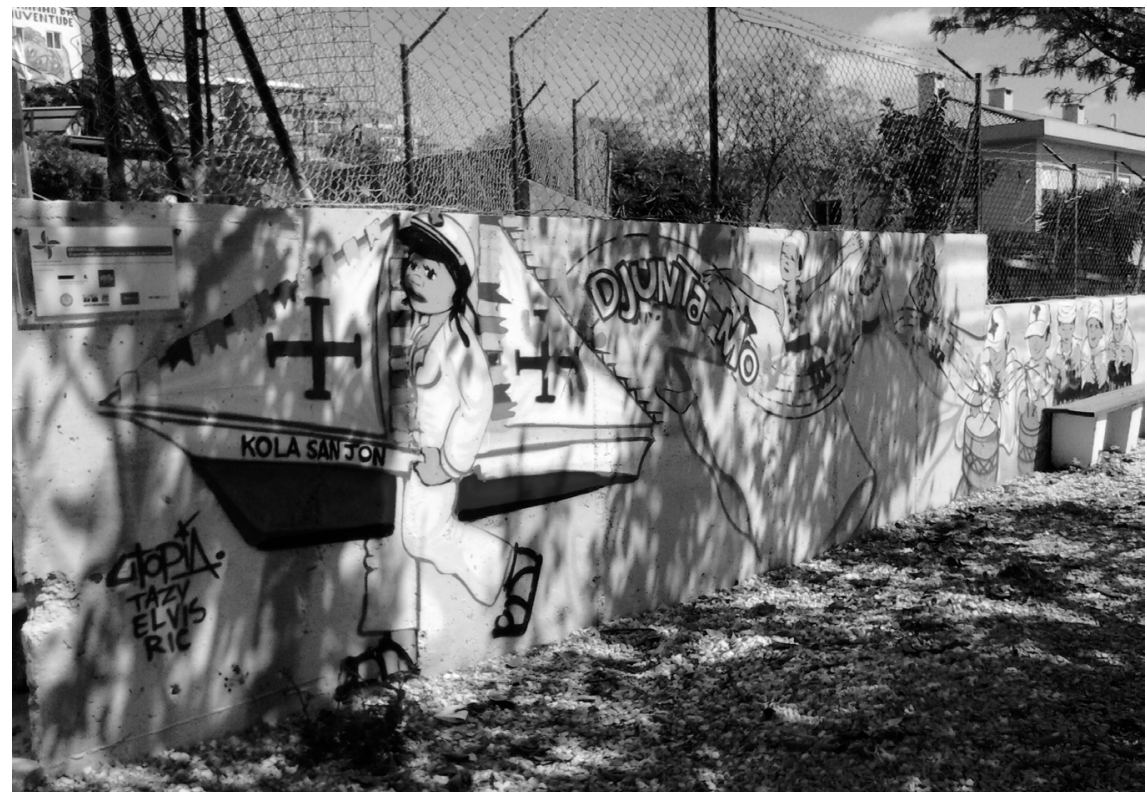

FUENTE FOTOGRAFÍA DEL AUTOR

A la precaria instalación de los nuevos vecinos en la Cova da Moura sucedió de inmediato una dura lucha por conseguir infraestructuras básicas para el barrio. La necesidad de luz y agua corriente, así como de un sistema de alcantarillado para el conjunto de los vecinos, los motivó a organizarse y desarrollar una labor continuada de exigencias frente a las instituciones públicas, incluyendo iniciativas como la presentación de instancias colectivas, recogidas de firmas y manifestaciones. Fue así como cuajó una primera asociación de vecinos, constituida en 1978, que desempeńó un papel determinante hasta mediados de los ańos ochenta. La población caboverdiana, que en estos años se encontraba en fuerte crecimiento, participó de esta asociación sin tener un excesivo protagonismo, pues el grueso de la actividad giraba en torno al liderazgo de vecinos portugueses, más antiguos en la zona. A medida que la dura lucha daba frutos y el barrio se iba adecentando, los caboverdianos fueron sintiéndose relegados en sus reivindicaciones dentro de la asociación. 
Comenzó a extenderse entre ellos una sensación de abandono frente a unos dirigentes vecinales autóctonos que, en la medida en que conseguían infraestructuras para las zonas centrales y más antiguas del barrio, fueron rebajando sus reivindicaciones, dificultando así que las mejoras urbanísticas llegaran a las zonas más altas y periféricas, que es donde se fueron asentando los nuevos vecinos caboverdianos.

Al principio, cuando estábamos en lucha por el agua, la gente no estaba directamente por hacer una asociación. Aquí existía una asociación de vecinos, que se preocupaba sobre todo de ordenar las calles y esas cosas. Nuestra lucha quedó un poco dificultada dentro de aquella asociación. Y me di cuenta de que aquello no estaba funcionando. (Adele, dirigente de la asociación Moinho da Juventude)

Ante la dificultad de canalizar sus demandas a través de la asociación de vecinos existente, los caboverdianos optaron por formalizar la Associaçáo Cultural Moinho da Juventude en 1987. El origen de esta asociación responde así a una situación de doble conflictividad: una de raíz externa, que obligó a los caboverdianos a organizarse en defensa de sus demandas frente a unas instituciones de gobierno que no los atendían; y otra de carácter interno, que los llevó a conformar su propia asociación frente a una población más antigua en el barrio, étnicamente portuguesa, que no asumía la urgencia de sus necesidades. Esta confluencia de factores empujó a la población caboverdiana hacia un proceso de autoorganización en que las necesidades materiales de los vecinos serían sistemáticamente conectadas con la reivindicación de su identidad cultural diferenciada.

La asociación Moinho da Juventude comenzó desplegando un ambicioso proyecto de intervención, que asumía como objetivo prioritario la dignificación del barrio a través de las lucha organizada por su mejora material y la construcción de un orgullo caboverdiano. La reivindicación de mejoras urbanísticas se dio en paralelo a la recuperación de una identidad que se iría filtrando progresivamente en los espacios y en los tiempos de este barrio. Desde la asociación se recabaron firmas para exigir alumbrado público y se conformó un grupo de batuka, que introdujo en las calles un sonido fuertemente asociado al archipiélago y muy especialmente a las islas de Barlovento. Se redactaron denuncias a las autoridades y se organizaron grupos de danzas que recuperaban para los vecinos prácticas tradicionales del país de origen. Se informaba a los vecinos de los problemas del barrio y se fue incluyendo en su calendario la celebración de los eventos centrales de Cabo Verde, como el Kola San Jon, una importante festividad que tiene lugar cada 24 de junio. Esta estrategia doble conseguiría que la lucha vecinal y el orgullo identitario se reforzaran recíprocamente.

Fue esta una apuesta que nosotros hicimos siempre, ¿no? Ver que a través de la cultura las personas sienten su dignidad. (Adele, dirigente de la asociación Moinho da Juventude) 
FIgURA 3 | Los vecinos danzan y ondean la bandera de Cabo Verde durante la fiesta de Kola San Jon 2014

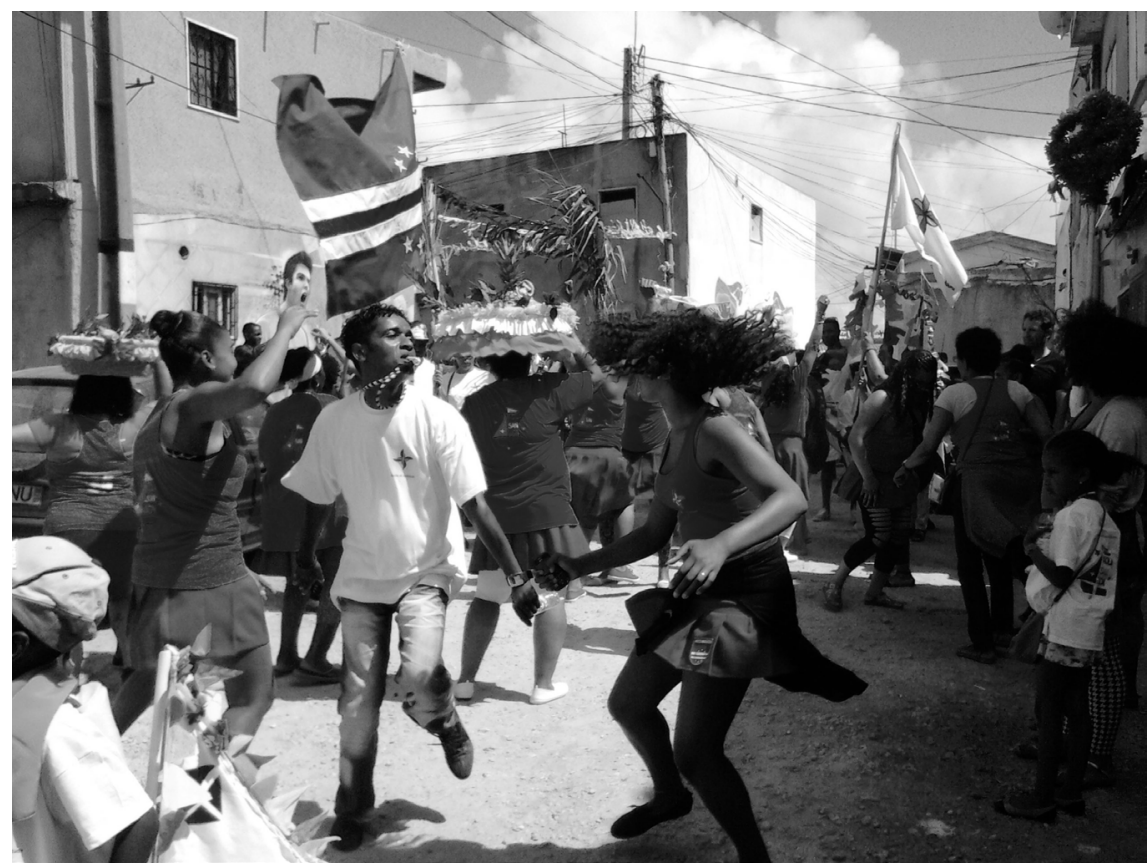

FUENTE FOTOGRAFÍA DEL AUTOR

En 1987, la asociación Moinho da Juventude asumió la forma de Institución Particular de Solidaridad Social (IPSS), una figura legal recogida en la Constitución portuguesa de 1976 para integrar en el nuevo sistema de Seguridad Social una amplia gama de instituciones caritativas que hasta entonces habían asumido numerosas funciones en la prestación de asistencia básica. Las IPSs tienen como objetivo cubrir servicios básicos allí donde el Estado no llega, y suelen centrar sus esfuerzos en la asistencia a menores, ancianos, discapacitados y marginados, normalmente mediante la promoción de la salud, la educación, la formación profesional y la asistencia en problemas residenciales. Las IPSs son organismos fiscalizados por el Estado portugués, tienen su propio régimen contributivo, y ostentan la capacidad de establecer acuerdos con la Seguridad Social portuguesa para la prestación financiada de servicios a la población. Este singular régimen legal permitió a la asociación Moinho da Juventude la suscripción de una serie de convenios con la Seguridad Social portuguesa para la prestación de servicios básicos en el barrio -guarderías, comedores, talleres-, lo cual a su vez la habilitó para captar fondos y contratar a vecinos para la gestión de esos servicios. La asociación pronto adquiriría una enorme legitimidad entre los vecinos, para convertirse en el emblema de la mayoría caboverdiana del barrio. Paralelamente reforzaba su presencia física en el barrio con la apertura progresiva de varios espacios, incluyendo un gran edificio de oficinas centrales, otro más pequeño para la prestación de servicios especializados -asesoría 
jurídica y laboral-, una casa de varias plantas con salas para actividades culturales, donada temporalmente por una familia que emigró a Francia, y otra más pequeña adecentada como biblioteca.

Ciertamente no todos los caboverdianos del barrio participaron por igual en la asociación ni asumieron su discurso. Algunos se fueron desmarcando y optaron por un uso estratégico del discurso asimilacionista, identificándose exclusivamente como vecinos lisboetas e incluso acusando a la asociación de contribuir con su práctica a reforzar la excepcionalidad cultural del barrio y, como consecuencia de ello, su marginación. No obstante, estas posturas son claramente minoritarias en el barrio. Parece evidente que los beneficios materiales logrados por la asociación, y muy especialmente su capacidad para contratar a vecinos del barrio, ha contribuido notablemente a arrinconar este tipo de disidencias.

El potente proceso de autoorganización entre la mayoría caboverdiana respondió directamente a la inoperancia de las instituciones políticas portuguesas, que en esos años - década de los ochenta- se abstuvieron de actuar en el barrio, sin llevar a cabo las medidas demandadas por los vecinos. Dicha actitud de pasividad fue percibida por la mayor parte de los vecinos como una afrenta y como una forma de discriminación institucionalizada. Tal sentimiento se agudizó a partir de 1993, cuando el barrio quedó excluido del Programa Especial de Realojamento (PER), ${ }^{5}$ cuyo objetivo era la erradicación de las barracas existentes en la ciudad mediante la concesión de apoyo financiero para la construcción, adquisición o arrendamiento de viviendas destinadas a realojar a las familias residentes en dichas unidades. Con un discurso de corte higienista, este programa produciría una transformación decisiva en todo el Área Metropolitana de Lisboa, a través de un conjunto de intervenciones prolongadas durante más de diez años. Sin embargo, y por darse prioridad a otros barrios, la Cova da Moura quedó fuera de su cobertura. Esta exclusión de los planes institucionales de recualificación de la zona actuó como un acicate en el proceso de autoorganización y de reafirmación identitaria.

\section{Luchando contra el estigma (2000-2015)}

A lo largo de veinticinco años, la Cova da Moura permaneció al margen de los programas reguladores que habían legalizado y adecentado otros barrios del entorno cuyo origen había sido similar. Durante un cuarto de siglo este barrio fue invisible para la Administración, lo que derivó en la consolidación de un problema que incluye, entre sus múltiples aristas, un serio conflicto sobre la titularidad de los terrenos. Esta pertenece legalmente a una familia que, durante este primer periodo, supo armonizar sus pretensiones con la estrategia de la Administración, que permitía la ocupación como un mal menor. Sin embargo, la entrada en el siglo xxi va a coincidir con una serie de transformaciones estructurales que afectarán profundamente la actitud de los actores involucrados. El escenario de fondo es una ciudad inmersa en un proceso de fuerte especulación inmobiliaria, donde la celebración de la Expo'98 y la mejora en infraestructuras contribuyeron a revalorizar el precio 
del suelo, especialmente en zonas céntricas y/o bien conectadas. En este contexto, los terrenos de la Cova da Moura experimentaron una fuerte subida en cuanto a su valor potencial, y pasaron a convertirse en un apreciado objetivo para urbanistas y especuladores.

Las administraciones públicas dieron muestras en lo sucesivo de un renovado interés en la zona, que se refleja en el despliegue de toda una batería de intervenciones orientadas a cambiar el perfil del barrio. La primera de ellas fue el Plan de Recualificación, implementado en el año 2001 por la Cámara Municipal de Amadora. Con un discurso higienista y el objetivo de transformar el parque de viviendas y el trazado urbanístico de la zona, esta iniciativa planteaba abiertamente la demolición del 80\% de las viviendas existentes en el barrio. El plan encontró en seguida la oposición frontal de la población del lugar, liderada por una comisión unitaria ${ }^{6}$ que aglutinaba varias asociaciones locales, incluyendo la potente Moinho da Juventude. Estas entidades recogieron firmas entre los vecinos para informar a los residentes de la problemática y expresar su rechazo generalizado al plan. En un argumentario construido por esta Comisión de Barrio se observan ya planteamientos que reflejan una conciencia clara respecto de la existencia de dos propuestas enfrentadas de territorialización para el barrio. Los representantes de la comisión denunciaron el plan como un ataque a los residentes, cuyas formas de ocupación del espacio eran consideradas parte de una historia y unas identidades singulares.

Muchos de los trazos del tejido urbano del barrio son marca y al mismo tiempo dispositivo propiciador de la riqueza de la sociabilidad y de la vida asociativa local, estando anclados en su origen, en la historia y en la cultura de sus "residentesconstructores", así como en la inversión que estos realizaron aquí a lo largo de tres décadas. (Comisión de barrio Alto da Cova da Moura, 2006)

Entramos así en una nueva fase, en que la resistencia organizada de los vecinos ya no va a tener su oposición en la pasividad institucional, sino en un nuevo interés que consideran ilegítimo y vinculado a la especulación inmobiliaria. En un barrio habitado por familias muy humildes, comienza a cundir la preocupación por un posible realojamiento en bloques de pisos que no desean y que tendrían que pagar en alquiler. Y se va extendiendo la convicción de que el Plan de Recualificación no se orienta a la mejora de la vida de los vecinos, sino a un proceso de gentrificación que pretende rentabilizar la subida del valor de los suelos de la zona. Frente a este plan, la mayor parte de los vecinos asume una posición de apego al barrio que se traduce en un discurso de reafirmación identitaria.

Se dibuja así una nueva lógica en que la identidad caboverdiana es reactivada como un eje de resistencia frente a la voluntad especuladora que se intuye en los planes institucionales de recualificación. Desde este momento, y a lo largo de los últimos quince años, la historia de la Cova da Moura ha sido una sucesión de litigios espoleados por el afán especulativo de los propietarios de los terrenos y de empresas constructoras interesadas. Esta presión especulativa se ha visto respaldada por una 
batería de planes urbanísticos que continúan la línea higienista anticipada por el PER y por el Plan de Recualificación de la Cámara de Amadora. Es el caso del Proyecto Urban in de las freguesías Damaia y Buraca, ${ }^{7}$ subvencionado con fondos europeos, cuyo objetivo fue introducir una transformación en profundidad del perfil urbano y social del barrio a partir de cuatro objetivos: (i) recualificar el ambiente urbano y valorizar el espacio público; (ii) integrar a la población africana; (iii) revitalizar el ambiente social; y (iv) valorizar el contexto socioeducativo de la población juvenil (Malheiros \& Mendes, 2007, p. 210). O el programa Bairros Críticos (Barrios Críticos), que el gobierno portugués implementó entre 2005 y 2013, incluyendo a la Cova da Moura junto a otras dos zonas con graves problemas de vulnerabilidad urbana y social: Lagarteiro (Porto) y Vale da Amoreira (Moita). Todas estas iniciativas fueron apuntalando un discurso político que construyó la Cova da Moura como un espacio anómalo (Garcés, 2014, p. 145) y como un caso de urgencia ante el que se debía intervenir.

La construcción de este discurso implicó una sobreexposición pública de los problemas de la zona, que en poco tiempo pasó a ser famosa en toda Portugal como ejemplo negativo de exclusión urbana y de falta de integración cultural. ${ }^{8}$. Desde fines de los noventa, el aumento del desempleo, unido a los efectos del largo proceso de abandono del barrio, fue favoreciendo la consolidación en su seno de un problema considerable de tráfico de drogas al menudeo que, a su vez, se vinculó directamente con episodios recurrentes de violencia, presencia de armas de fuego y ejecución periódica de intervenciones policiales en la zona. Todos estos ingredientes dieron como resultado un escenario conflictivo que despertó el interés de los medios de comunicación, que a su vez también contribuyeron a difundir una imagen muy negativa del barrio, con la que los vecinos no se identifican.

La imagen del barrio es mala, y la culpa es sobre todo de los medios de comunicación. Porque solo muestran lo malo y no muestran lo bueno. Solo enseñan delincuencia, y nunca enseñan las actividades de los jóvenes y otras cosas. (Carlo Andrade, descendiente de caboverdianos, vecino del barrio)

Desde la Asociación Moinho da Juventude se ha hecho una lectura muy crítica de este proceso de estigmatización del barrio. Sus líderes lo interpretan como directamente ligado a los intereses especulativos que presionan a los vecinos, considerando así que la difusión de una imagen de la Cova da Moura como lugar peligroso forma parte de una estrategia de depauperización de la zona que persigue, en último término, la expulsión de la población residente:

Este barrio está en un sitio muy bueno: cerca de Lisboa, cerca de Sintra, cerca de Cascais. Tiene una localización óptima. Y está construido sobre una colina, y

7 La Cova da Moura pertenece a la freguesía de Buraca. La freguesía ('parroquia', organización administrativa en que se divide un municipio o concelho) representa el más bajo nivel del sistema administrativo portugués, justamente por debajo de las Cámaras Municipales. La Cámara Municipal es el órgano ejecutivo colegial de cada uno de los municipios de Portugal, es decir, su gobierno.

8 En el año 2007 el diario español El País publicó un reportaje sobre este barrio con el significativo título "Cova da Moura: retratos del último gueto africano". Véase en http://internacional.elpais. com/internacional/2007/03/23/actualidad/1174604401_850215.html 
también es óptimo, porque tiene aquí una vista óptima. Por eso la especulación inmobiliaria está muy interesada en este terreno. (...) Estigmatizaron mucho el barrio desde 2002, porque había un plan para hacer aquí: arrasar el barrio. (...) El plan que hicieron era echar abajo el ochenta por ciento del barrio, y solo quedaba el veinte por ciento. (...) Nosotros teníamos que salir y después vendrían aquí personas con más dinero. (Adele, dirigente de la asociación Moinho da Juventude)

Frente al problema de la invisibilidad que en otro momento lamentaron, los vecinos enfrentan ahora la difusión abusiva de imágenes que presentan el barrio como un gueto peligroso. Esto los ha llevado a priorizar entre sus estrategias una serie de iniciativas orientadas a combatir el estigma. Se trata de medidas con las que intentan difundir una imagen alternativa de la Cova da Moura, que valoriza la historia del barrio y dignifica a su población. Lo interesante en este punto es que, una vez más, estas estrategias girarán alrededor de la identidad caboverdiana.

Explotando un discurso alternativo, que conecta de forma irónica con la imagen institucional de Lisboa que reivindica el cosmopolitismo y la multiculturalidad de la ciudad, la Cova da Moura desarrolla un proceso de autoconstrucción como barrio caboverdiano. Se aprecia una estrategia organizada para visibilizar a todos los niveles el origen caboverdiano de la mayoría de sus vecinos, que es reconstruido como motivo de orgullo y como fuente de riqueza cultural para la capital portuguesa. Dicha estrategia entraña una serie de transformaciones urbanas que cargan de significado los espacios del barrio y los ligan de manera expresa a la idea de una identidad caboverdiana en el exilio. Así, todo el barrio se ha ido llenando de grafitis que representan imágenes de fuerte contenido caboverdiano, africano o incluso genéricamente negro, incluyendo los colores de la bandera, mapas de las islas o retratos de Amílcar Cabral.

FIgURA 4 | Dos grafitis en el barrio: a) "Unidade e Luta", retrato de Amilcar Cabral; y b) "Eu tenho um sonho", retrato de Martin Luther King
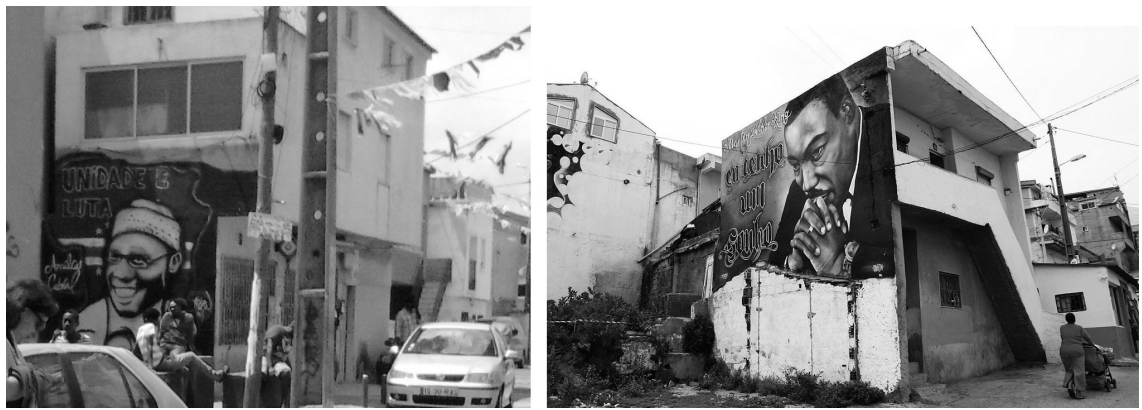

FUENTE FOTOGRAFÍAS DEL AUTOR

Debe notarse nuevamente que frente a esta estrategia colectiva mayoritaria no han faltado en el barrio actitudes de resistencia entre parte del vecindario. Algunos residentes se muestran críticos con este proceso de afirmación creciente de la caboverdianidad, y asumen el discurso de las instituciones portuguesas, que presenta la singularidad cultural del barrio como un factor agravante de sus problemas. Pero, una vez más, estas voces han sido minoritarias, y la mayoría de los vecinos 
han respaldado de manera inequívoca la estrategia de la reafirmación identitaria nucleada en torno a la asociación Moinho da Juventude.

Así, dentro de un trazado laberíntico de calles estrechas, que contrasta fuertemente con el ordenamiento rígido de los barrios de viviendas sociales del entorno, las calles han sido rebautizadas con nombres que evocan lugares, expresiones o personajes propios de la historia de Cabo Verde. Esta práctica constituye un desafío radical al modelo de ordenación urbana predominante y una afirmación de la legitimidad exclusiva de los vecinos sobre este territorio (Duminy, 2014). Tanto en los letreros que adornan las calles como en el conjunto de las iniciativas de los vecinos, lideradas por la asociación Moinho da Juventude, se observa un proceso de recuperación y visibilización de palabras del criollo. Esta lengua, mayoritaria en las islas y largamente denostada como un dialecto vulgar, ha pasado a ser portadora de un sentido de orgullo y reafirmación identitaria. El barrio reivindica ahora palabras como sabura o morabeza, e incluso rescata el uso estético de la $k$ como letra característica en la redacción escrita del criollo.

FIGURA 5 | Una placa identifica al restaurante "Cantinho do Sossego" en el Routeiro das Ilhas, destacando el origen de sus propietarios en la isla de Santo Antão

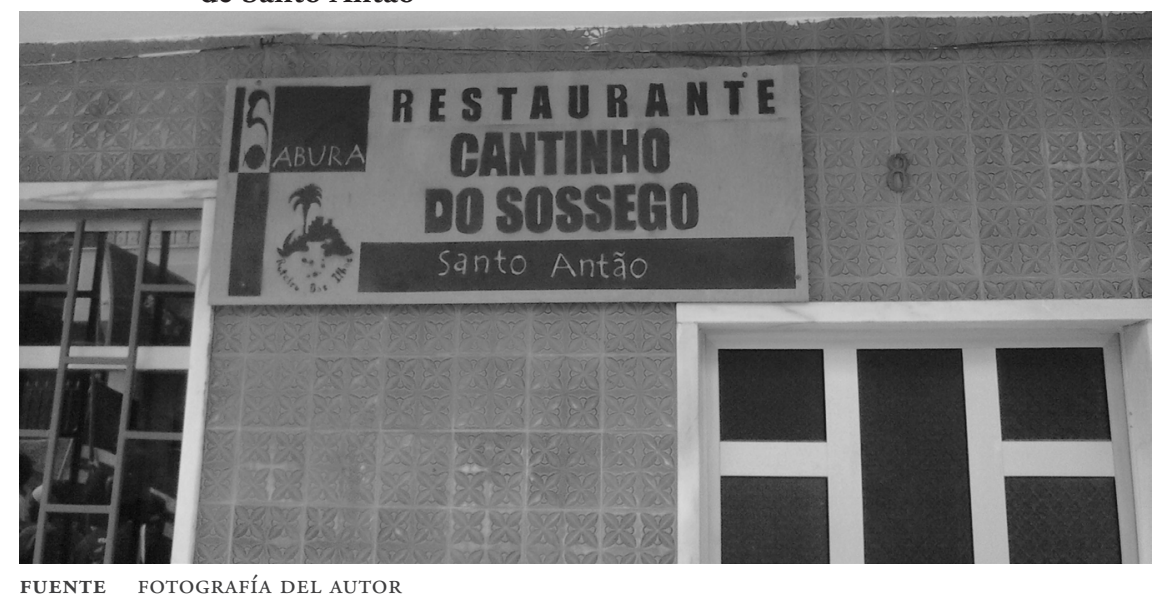

Precisamente Sabura (alegre, placentero) es el nombre dado a un proyecto que, dentro del proceso de reafirmación identitaria, marca la subida de un último peldańo. Esta iniciativa, respaldada por la asociación Moinho da Juventude, consiste en la organización de visitas al barrio para gente del exterior. Con este régimen de visitas se pretende combatir el estigma, desarticulando la imagen de la Cova da Moura como un sitio peligroso y ofreciendo en su lugar un retrato amable y pintoresco de un espacio caboverdiano. Las visitas son guiadas por jóvenes de la asociación a través de un recorrido prefijado que lleva el título de Routeiro das ilhas (Ruta de las islas), y que construye simbólicamente el paseo por el barrio como un acercamiento a la historia y la identidad de los inmigrantes caboverdianos. A lo 
largo de estas excursiones los visitantes descubren las peluquerías afro de la zona, los bares y restaurantes especializados en platos caboverdianos y un conjunto desordenado de callejones cuyos colores, olores y sonidos reflejan permanentemente una idea de la caboverdianidad en la distancia.

Tanto el proyecto Sabura como el conjunto de intervenciones urbanísticas implementadas a través de la asociación Moinho da Juventude han ido incorporando como prioridad la lucha contra el estigma. Este combate a la mala imagen del barrio forma parte, a su vez, de una estrategia para contrarrestar su deterioro y, en la misma medida, evitar la agudización de problemas que terminen justificando la intervención externa y una reordenación urbana que propicie la expulsión de los actuales vecinos. La Cova da Moura, rebautizada significativamente como Kova-M, se esfuerza así por resistir la presión especulativa y retener en su seno a los inmigrantes que la construyeron.

\section{Conclusiones}

Los datos recogidos en este artículo demuestran que la identidad caboverdiana ha desempeñado un papel central en las pautas de territorialización de la Cova da Moura durante más de cuatro décadas. Lejos de haber sido abandonada en el transcurso de los ańos, esta identidad se ve crecientemente reafirmada por los vecinos, y activada en conexión con formas organizadas de respuesta a los principales problemas del barrio. En este sentido, la afirmación de una identidad étnica diferenciada opera como un factor que refuerza las estrategias de integración de la población local, dotándola de referentes culturales y códigos compartidos a partir de los cuales afrontar su realidad cotidiana. Estos datos confirman, por tanto, que en un contexto de conflicto urbano, la etnicidad opera como un recurso estratégico, más que como una forma de lealtad primordial a la sociedad de origen.

La reafirmación de la identidad caboverdiana se ha plasmado en un ejercicio de intervención permanente sobre los espacios del barrio, que han sido dotados sistemáticamente de usos, formas y significados coherentes con las necesidades de los vecinos. Esta constatación refuerza las observaciones apuntadas sobre la importancia de las formas de apropiación del espacio urbano como estrategias de resistencia entre grupos subalternos. En el marco de este proceso de apropiación, delimitación y significación de los espacios del barrio, la importancia de la etnicidad aparece como una constante que, sin embargo, evoluciona de manera cambiante en función de las circunstancias. Así, en una primera fase, el recurso a la identidad caboverdiana será notable especialmente en la recuperación de referentes culturales que permiten la autoorganización de los vecinos y la consolidación de un fuerte sentido de comunidad, que resulta necesario para la construcción física del barrio y su equipamiento básico. Así lo demuestra el recurso sistemático al djunta-mon y la reivindicación de la cultura propia para la conformación de la asociación Moinho da Juventude. En una segunda fase, la identidad caboverdiana será reactivada en torno a un discurso de orgullo y como respuesta a un proceso acelerado de estigmatización del barrio. Elementos como el criollo, la comida o la música caboverdianas van a ser deliberadamente visibilizados hacia el exterior, y se va a hacer un uso más 
explícito de la conexión entre el territorio del barrio y la identidad caboverdiana de sus vecinos. Esta evolución de las formas de articulación de la etnicidad es coherente con el carácter estratégico, y no primordial, de esta lealtad identitaria.

La evolución discontinua de este proceso de territorialización es, por otra parte, indisociable de los fuertes conflictos que han atravesado el barrio a lo largo del tiempo. Tras una primera fase de abandono, en que los vecinos tuvieron que dotar al barrio de espacios públicos y privados ante el desinterés y el olvido de las autoridades municipales, los últimos años de los noventa alumbran un nuevo periodo de crecimiento económico que irá acompañado de una fuerte presión especulativa sobre la zona. Si en la primera fase las autoridades municipales se mostraron despreocupadas respecto de la ocupación de terrenos, que fue permitida de facto como un mal menor, la segunda fase va a incorporar la presencia de un proyecto alternativo de territorialización para el barrio: el pretendido por inversores privados y especuladores, y respaldado por las instituciones públicas a través de programas de intervención urbanística. Será la emergencia de este otro proceso de territorialización el que refuerce entre los vecinos la necesidad de organizarse en defensa de su barrio. Y será este nuevo escenario el que alumbre una segunda fase de conflicto urbano en la zona: el que enfrenta el proyecto especulador de actores externos al barrio -bancos, inmobiliarias y cámara municipal- con el proyecto de los vecinos por seguir habitándolo. La estrategia de los primeros, basada en gran medida en estigmatizar el barrio para justificar la intervención externa, será clave para entender la respuesta de los segundos, reorientada hacia el combate al estigma y la reafirmación orgullosa de lo caboverdiano como patrimonio del barrio y de la ciudad. Resulta importante en este punto subrayar cómo, en un escenario de conflicto urbanístico, la iniciativa institucional no es culturalmente neutra, sino que entraña formas de adhesión -implícitas o explícitas- a un modelo de ciudad estandarizado a partir de criterios culturalmente construidos.

Observamos, en definitiva, un proceso en el que las formas de conflicto urbano se encabalgan con las estrategias organizativas de los vecinos, determinando el papel central de la identidad étnica en ellas. La etnicidad es la base que sustenta un conjunto articulado de formas de intervención sobre el territorio, que reivindican la propiedad legítima de estos espacios para los vecinos de origen inmigrante frente al proyecto higienista, que pretende reasentarlos en otras zonas de la ciudad. Esta centralidad de la etnicidad caboverdiana en la Cova da Moura nos remite de manera directa a las nuevas formas de conflicto que atraviesan la periferia urbana en el contexto posfordista, donde las desigualdades son reorganizadas en torno a criterios de segmentación étnica y sobre la exclusión jurídica, política y económica de las poblaciones inmigrantes. Esta renovada importancia de la etnicidad atestigua, por otra parte, la importancia que el espacio urbano continúa teniendo en tanto recurso en disputa en el marco de las sociedades capitalistas. En torno a este recurso siguen desenvolviéndose conflictos que determinan tanto la disposición física de los espacios de la ciudad como los usos y significados que se les asocian. En el caso tratado, llama particularmente la atención la manera singular en que una mayoría caboverdiana de vecinos reivindica la legitimidad de su control sobre el espacio de la Cova da Moura. En ella se advierte una tendencia aparentemente paradójica: 
la afirmación de la otredad étnica -el origen extranjero- es parte importante del discurso de reivindicación del territorio. Esta fórmula aparece con más frecuencia en sentido inverso: suelen ser los autóctonos quienes, precisamente por serlo, movilizan su identidad étnica para reclamar un control exclusivo sobre el territorio. La Cova da Moura ofrece así un singular caso de estudio, que demuestra las formas complejas del conflicto urbano en su articulación con estrategias de construcción y reconstrucción identitaria, y que aconsejan continuar profundizando en un análisis teórico relacional sobre procesos migratorios, identidades y conflicto urbano.

\section{Referencias bibliográficas}

Augé, M. (2002). Los no lugares. Espacios del anonimato. Barcelona: Gedisa.

Batalha, L. (2008). Cabo-verdianos em Portugal: “comunidade” e identidade. En P. Góis (Org.), Comunidade(s) cabo-verdiana(s): as múltiplas faces da imigração cabo-verdiana (pp. 2536). Lisboa: Alto Comissariado para a Imigração e Diálogo Intercultural (ACIDI).

Cuberos-Gallardo, F. J. (2009). Redes sociales e integración de los inmigrantes. El caso de las mujeres ecuatorianas residentes en Sevilla. Revista Interdisciplinar da Mobilidade Humana, 17(32), 61-80. http://www.csem.org.br/remhu/index.php/remhu/article/ view/164

Cuberos-Gallardo, F. J. (2014). La identidad en juego: las ligas de fútbol como espacio-tiempo para la reproducción cultural entre inmigrantes. Scripta Nova. Revista Electrónica de Geografia y Ciencias Sociales, 18(468). http://www.ub.edu/geocrit/sn/sn-468.htm

Carita, C. \& Rosendo, V. N. (1993). Associativismo cabo-verdiano em Portugal. Estudo de caso da Associação Cabo-verdiana em Lisboa. Sociologia. Problemas e práticas (13), 135-152. http://sociologiapp.iscte-iul.pt/fichaartigo.jsp?pkid=274

Castells, M. (1977). The urban question. Londres: Edgard Arnold.

Castells, M. (1997). The power of identity. Cambridge, MA: Blackwell Publishers.

Castles, S. (1998). Globalización y migración: algunas contradicciones urgentes. Revista Internacional de Ciencias Sociales (156), 54-68. http://www.ub.edu/prometheus21/ articulos/nautas/18.pdf

Duminy, J. (2014). Street renaming, symbolic capital, and resistance in Durban, South Africa. Environment and Planning D: Society and Space (32), 310-328.

Garcés, A. (2006). Configuraciones espaciales de lo inmigrante: usos y apropiaciones de la ciudad. Papeles del CEIC (20), 1-34. http://www.ehu.eus/ojs/index.php/papelesCEIC/ article/view/12145/11067

Garcés, A. (2014). Contra el espacio público: criminalización e higienización en la migración peruana en Santiago de Chile. EURE, 40(121), 141-162. http://doi.org/10.4067/ S0250-71612014000300007

Glazer, N. \& Moynihan, D. P. (1979). Beyond the melting pot: the negroes, puerto ricans, jews, italians and irish of New York City. Cambridge, MA: MIT Press.

Gurak, D. T. \& Caces, F. (1998). Redes migratorias y la formación de sistemas de migración. En G. Malgesini (Ed.), Cruzando fronteras. Migraciones en el sistema mundial (pp. 75110). Madrid: FUHEM-Icaria. 
Hall, S. (1995). New cultures for old. En D. Massey \& P. Jess (Eds.), A place in the world? Places, cultures and globalization (pp. 175-214). Oxford: Oxford University Press.

Harvey, D. (1973). Social justice and the city. Baltimore: Johns Hopkins University Press.

Hutchinson, J. \& Smith, A. D. (1996). Ethnicity. Oxford: Oxford University Press.

Isin, E. F. (2000). Introduction: Democracy, citizenship and the city. En E. F. Isin (Ed.), Democracy, citizenship and the global city (pp.1-21). Nueva York: Routledge.

Law, L. (2002). Defying disappearance: Cosmopolitan public spaces in Hong Kong. Urban Studies, 39(9), 1625-1645. http://journals.sagepub.com/toc/usja/39/9

Lefebvre, H. (1991). The production of space. Oxford: Blackwell.

Lojkine, J. (1981). El marxismo, el Estado y la cuestión urbana. México, DF: Siglo XxI.

Machado, F. L. (1999). Imigrantes e estrutura social. Sociologia. Problemas e práticas (29), 5176. http://sociologiapp.iscte-iul.pt/pdfs/11/120.pdf

Malheiros, J. M. \& Mendes, M. (Coords.). (2007). Espaços e expressóes de conflito e tensão entre autóctones, minorias migrantes e não migrantes na área metropolitana de Lisboa. Lisboa: Alto Comissariado para a Imigração e Diálogo Intercultural (ACIDI).

Martín, E. (1990). Las asociaciones andaluzas en Cataluña y su funcion de reproducción de la identidad cultural. En J. Cucó \& J. J. Pujadas (Coords.), Identidades colectivas. Etnicidad y sociabilidad en la Peninsula Ibérica (pp. 255-268). Valencia: Generalitat Valenciana.

Martín, E. \& Pujadas, J. J. (1999). Movilización étnica, ciudadanía, transnacionalización y redefinición de fronteras: una introducción al tema. En J. J. Pujadas, E. Martín \& J. Pais de Brito (Coords.), Globalización, fronteras culturales y politicas y ciudadanía (pp. 7-16). Santiago de Compostela: Asociación Galega de Antropoloxía.

Pujadas, J. J. (1990). Identidad étnica y asociacionismo en los barrios periféricos de Tarragona. En J. Cucó \& J. J. Pujadas (Coords.), Identidades colectivas. Etnicidad y sociabilidad en la Península Ibérica (pp. 307-323). Valencia: Generalitat Valenciana.

Sardinha, J. (2004). O associativismo caboverdiano na Área Metropolitana de Lisboa e a inserção da comunidade caboverdiana na sociedade portuguesa. Atas do VIII Congresso Luso-Afro-Brasileiro de Ciências Sociais. Coimbra, 16 al 18 de septiembre.

Sardinha, J. (2009). Immigrant associations, integration and identity: Angolan, Brazilian and Eastern European Communities in Portugal. Ámsterdam: Amsterdam University Press.

Sassen, S. (2000). The global city: Strategic site/new frontier. En E. F. Isin (Ed.), Democracy, citizenship and the global city (pp. 48-61). Nueva York: Routledge.

Sassen, S. (2003). Contrageografias de la globalización. Género y ciudadanía en los circuitos transfonterizos. Madrid: Traficantes de sueños.

Servicio de Extranjeros y Fronteras (2013). Relatório de Imigração, Fronteiras e Asilo - 2012. Oeiras: Serviço de Estrangeiros e Fronteras.

Thomas, W. I. \& Znaniecki, F. (2004). El campesino polaco en Europa y América. Madrid: Centro de Investigaciones Sociológicas, Boletín Oficial del Estado.

Winchester, H. P. M., Kong, L. \& Dunn, K. (2003). Landscapes: Ways of Imagining the World. Harlow: Pearson Prentice Hall. 